\title{
Importance of preabsorptive insulin release on oral glucose tolerance: studies in pancreatic islet transplanted rats
}

\author{
E G SIEGEL, E R TRIMBLE, A E RENOLD, AND H R BERTHOUD \\ From the Institut de Biochimie Clinique and Laboratoires de Recherches Medicales, University of Geneva, \\ Geneva, Switzerland
}

SUMMARY The role of preabsorptive (cephalic phase) insulin release in oral glucose tolerance was investigated using diabetic rats treated by intraportal transplantation of isogenic islets. This early neurally mediated phase of insulin release has been shown to be absent in such rats. When the body weight of transplanted rats was normalised, glucose tolerance tests (GTTs) were performed in the unstressed state using permanent cardiac catheters. Transplanted rats had a normalised intravenous GTT, whereas, as we have shown previously, their oral GTT remained clearly pathological. During both tests peripheral insulin levels were decreased compared with controls. While during intravenous GTT the onset of insulin release occurred as early in transplanted rats as in controls, during oral GTT there was a clear delay, probably because of the absence of the cephalic phase. Re-establishment of normal preabsorptive insulin levels was attempted by a small intravenous insulin injection during this period. This resulted in a transient increase in peripheral insulin levels, which, at two minutes after glucose ingestion, gave values similar to those found in controls at that time. This small insulin injection caused a marked improvement of the oral GTT which was most evident after exogenous insulin had disappeared from the blood. While the injection did not affect the 60 minute incremental insulin area, the glucose area was decreased by $50 \%$, to a value not significantly different from that of control rats. The cephalic phase of insulin release appears, therefore, to be one important factor in the control of glycaemia during food intake. Its absence plays a major role in the pathological oral glucose tolerance of diabetic rats treated by intraportal islet transplantation.

It has long been known that the disposal of orally ingested glucose is controlled not only by the increase in blood glucose concentration, but also by other factors such as gastrointestinal hormones and neural reflexes. ${ }^{1}$ Neural influences may be of particular importance when transplantation of pancreatic endocrine tissue is performed, as the transplant may remain denervated. We have shown, for example, that when a sufficient number of islets is transplanted to normalise the intravenous glucose tolerance in the unstressed rat, oral glucose tolerance in the same animals remains abnormal. ${ }^{2}$ Whereas after an intravenous glucose load plasma insulin levels rose as early in transplanted rats as in controls, after an oral glucose load transplanted rats displayed a delayed plasma insulin response. When tests

Received for publication 22 July 1980 designed to measure preabsorptive (cephalic phase) insulin release were performed, it was found that this part of the early insulin response was absent in islet-transplanted rats, ${ }^{3}$ as reported previously for diabetic rats treated by foetal pancreas transplants. ${ }^{4}$ It is known that the early insulin response after both intravenous ${ }^{56}$ and oral $^{478}$ glucose loading is an important determinant of the overall glucose tolerance. Therefore, the present study was designed to define the importance of preabsorptive insulin release-or its absence-in maintaining normal oral glucose tolerance in previously diabetic rats treated by intraportal islet transplantation. To this end, islet transplanted rats had oral glucose tolerance tests performed with and without a small injection of insulin given intravenously during the preabsorptive period, in a dose calculated to mimic the levels seen during cephalic phase secretion. As stress affects glucose tolerance in islet transplanted 
rats even more than in normal animals, ${ }^{9}$ care was taken to test animals in the conscious unstressed state.

\section{Methods}

\section{ANIMALS}

Highly inbred male Wistar-Lewis rats obtained from the Charles-River Breeding Laboratories, Wilmington, Mass., were used. After food had been withdrawn for 12 to 16 hours, diabetes was induced in rats weighing $200-250 \mathrm{~g}$ (8-10 weeks old) by the intravenous injection of streptozotocin $(50 \mathrm{mg} / \mathrm{kg})$ freshly dissolved in acidified saline ( $\mathrm{pH} 4 \cdot 5)$. Control rats received an intravenous injection of acidified saline. Islet transplantation or sham operation was performed four to five weeks later. Islets were isolated by a modification of the collagenase technique. ${ }^{10} \mathrm{After}$ hand-picking, the islets were suspended in modified Krebs-Ringer bicarbonate (KRB) buffer containing $\mathrm{Na}^{+} 145 \cdot 6, \mathrm{~K}^{+} 6 \cdot 0, \mathrm{Ca}^{++} 2 \cdot 0$, $\mathrm{Mg}^{++} 2 \cdot 4, \quad \mathrm{Cl}^{-} 127 \cdot 8, \quad \mathrm{PO}_{4}{ }^{-}-1 \cdot 2, \quad \mathrm{SO}_{4}{ }^{-}-2 \cdot 4$, $\mathrm{HCO}_{3}-24.6 \mathrm{mEq} / \mathrm{l}, 5.5 \mathrm{mM}$ glucose, and $1 \%$ bovine serum albumin. An aliquot was taken from each batch of islets for measurement of insulin content. A known number of islets was then placed in a siliconised glass syringe containing $0 \cdot 2-0 \cdot 3 \mathrm{ml}$ KRB buffer. The recipient rat was anaesthetised with sodium pentobarbital. The abdomen was opened through a midline incision and the portal vein exposed. A 23-gauge needle, connected by a fine catheter to the syringe, was inserted into the portal vein and the islets were slowly injected. After the injection, the syringe, catheter, and needle were repeatedly flushed into a Petri dish and the remaining islets were counted.

\section{GLU COSE TOLERANCE TESTS}

Thirteen to 15 weeks after transplantation or sham operation of non-diabetic control rats, permanent cardiac catheters were implanted via the jugular vein according to the method of Steffens. ${ }^{11}$ These catheters were filled with a $60-70 \%$ polyvinylpyrrolidone (PVP) solution containing heparin $500 \mathrm{U} / \mathrm{ml}$ and penicillin $20000 \mathrm{U} / \mathrm{ml}$; the mixture was aspirated every second day and the whole catheter was flushed out with heparinised saline and then refilled with the PVP/heparin/saline solution. By this means catheters could be used for six to eight weeks. Animals were housed individually in special cages, handled frequently, and all tests were carried out in their home cages. The tests were started one to two weeks after catheter implantation when the rats had returned to a normal rate of weight gain.

The rats were habituated to the blood-sampling procedure and to drinking a glucose solution when it was presented. Tests were performed in the afternoon, six to eight hours after food withdrawal. Before the test, an extension tube was attached to the cardiac catheter, 50-100 U heparin was given per rat, and 20 to 30 minutes later the tests were begun. After two basal blood samples glucose was injected via the cardiac catheter or presented in a petri dish for oral consumption. Zero time for the oral test was when the rat spontaneously began to drink the glucose solution, and for the intravenous test when glucose was injected. After intravenous glucose loading, the catheter was flushed through several times with saline to remove any traces of glucose. The glucose loads and blood-sampling times for each test are as follows:

IVGTT Glucose load $1 \mathrm{~g} / \mathrm{kg}$ ( $40 \%$ glucose solution). Sampling times: basal (twice), 2, 5, 10, 20, 40, and 60 minutes.

OGTT Glucose load $1 \mathrm{~g} / \mathrm{kg}$ and $2 \mathrm{~g} / \mathrm{kg}(40 \%$ glucose solution). Sampling times: basal (twice), 2, 5, 10, 20, $40,60,90$, and 120 minutes.

\section{ORAL GTT $(1 \mathrm{~g} / \mathrm{kg})$ WITH INSULIN INJECTION}

The procedure was similar to the above except that an intravenous injection of Actrapid insulin (Novo) was given during the first minute (55-60 s) after the rat had started to take the glucose. The dose of insulin was calculated to mimic the concentration found in peripheral veins during cephalic phase release. These calculations were made taking into account the known disappearance rate of intravenously injected insulin in rats ${ }^{12}$ and adjusted empirically after pilot experiments in normal rats under basal conditions. Each blood sample was $200 \mu \mathrm{l}$. The total blood withdrawn was therefore small (1.6-2 ml) and it was replaced at the end of each test. The time interval between tests was three to five days.

PANCREAS AND ISLET EXTRACTION FOR DETERMINATION OF INSULIN CONTENT Immediately after death the pancreata were removed, weighed, and stored at $-20^{\circ} \mathrm{C}$. Insulin was extracted by a modification of the Kenny technique, ${ }^{13}$ using acidified ethanol $(0.7 \mathrm{M} \mathrm{HCl} /$ ethanol, $1: 3$ $\mathrm{v} / \mathrm{v})$. Acidified ethanol was also used for the extraction of islet insulin from the isolated islets.

\section{ASSA Y S}

Plasma and urinary glucose concentrations were measured by a glucose oxidase method. ${ }^{14}$ Immunoreactive insulin was measured according to Herbert et al. $^{15}$ using rat insulin standard and guinea-pig antipork insulin serum. 
MATERIALS

Streptozotocin was a gift from $\mathrm{Dr}$ W J Dulin, Upjohn Company, Kalamazoo, Michigan. Collagenase (type IV) was obtained from Serva $\mathrm{GmbH}$, Heidelberg, West Germany. Rat insulin standard was obtained from $\mathrm{Dr}$ J Schlichtkrull, Novo Research Institute, Bagsvaerd, Denmark. Guinea-pig anti-insulin serum was a gift from $\mathrm{Dr} \mathrm{H}$ H Schone, Farbwerke Hoechst, Frankfurt, West Germany. Insulin Actrapid was obtained from Novo Industri, Copenhagen, Denmark.

\section{PRESENTATION OF RESULTS AND}

STATISTICAL METHODS

Results are given as mean \pm SEM unless stated otherwise. The glucose and insulin areas for the various glucose tolerance tests were calculated by integrating the incremental glucose and insulin concentrations above basal for each animal. Student's two-tailed unpaired $t$ test was used to evaluate differences between transplanted rats and controls. Student's two-tailed paired $t$ test was used to assess differences between the oral GTTs with and without injected insulin in the same animal.

\section{Results}

TRANSPLANTED ISLETS

The number of islets injected per animal was $2106 \pm$ 266. The mean insulin content of these islets was $27 \cdot 9 \pm 2.1 \mathrm{ng} /$ islet so that the total insulin content of the islets transplanted to each rat was approximately $59 \mu \mathrm{g}$. The mean pancreatic insulin content for the rat strain at this age was found to be $96 \pm 10$ $\mu \mathrm{g} /$ pancreas $(\mathrm{n}=5)$ so that the amount of insulin contained in the transplanted islets corresponded to about $62 \%$ of the content of one normal rat pancreas.

\section{DEVELOPMENT OF BODY WEIGHT}

The body weight of transplanted rats and of diabetic and non-diabetic controls is shown in Fig. 1. Animals injected with streptozotocin stopped gaining weight. They, in fact, lost about $10 \mathrm{~g}$ over the period of investigation. Not all diabetic controls survived for the whole period, however, so that the value shown for six surviving animals corresponds to a positive selection. After four weeks of diabetes (zero time, Fig. 1) the mean weight of the recipient rats was about $75 \mathrm{~g}$ less than that of the age-matched non-diabetic controls at the time of transplantation. Rapid weight gain occurred after transplantation, so that from the eighth week onwards no significant difference was observed between transplanted rats and non-diabetic controls. Transplanted rats gained $223 \pm 21 \mathrm{~g}$ and non-diabetic controls $164 \pm 14$ $(\mathrm{P}<0.05)$ during the 14 weeks after transplantation.

\section{METABOLIC STATE OF DIABETIC RATS BEFORE}

AND AFTER TRANSPLANTATION

The urine volume of diabetic rats before transplantation was $148 \pm 13 \mathrm{ml} / 24 \mathrm{~h}$ and the glucose excretion $12 \cdot 7 \pm 1 \cdot 7 \mathrm{~g} / 24 \mathrm{~h}$. After transplantation the urine volume decreased rapidly, reaching $10 \pm 2 \mathrm{ml} /$ $24 \mathrm{~h}$ in the second week, a volume no longer significantly different from non-diabetic controls $(6 \pm 2 \mathrm{ml} / 24 \mathrm{~h}$, range $4-12 \mathrm{ml})$. Urine volumes remained stable after the third week. Urine was free from glucose as measured by Testape (Lilly), from the second week onwards. The mean plasma glucose in rats before transplantation was $37 \cdot 1 \pm 2 \cdot 4 \mathrm{mmol} / \mathrm{l}$

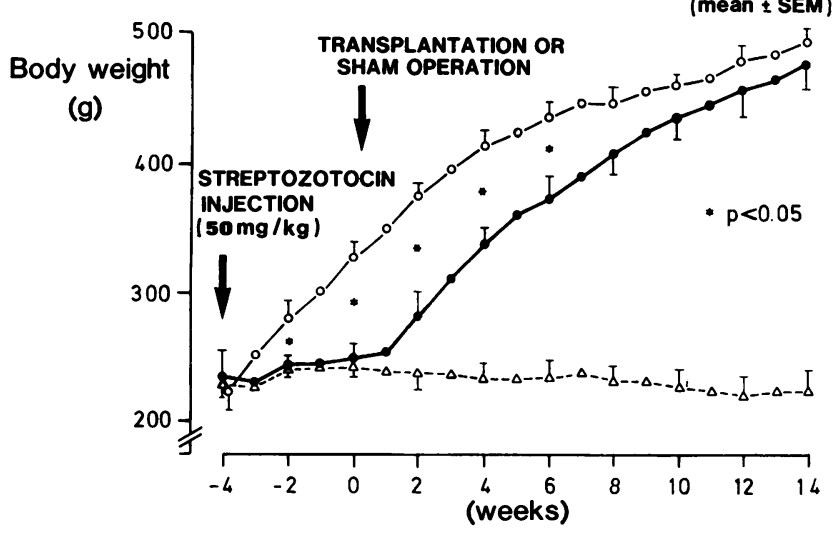

Fig. 1 Development of body weight in rats after islet transplantation. Rats were transplanted or sham-operated four to five weeks after streptozotocin injection $(50 \mathrm{mg} / \mathrm{kg})$. Permanent venous catheters for use in glucose tolerance tests were implanted 13 to 15 weeks after transplantation. 

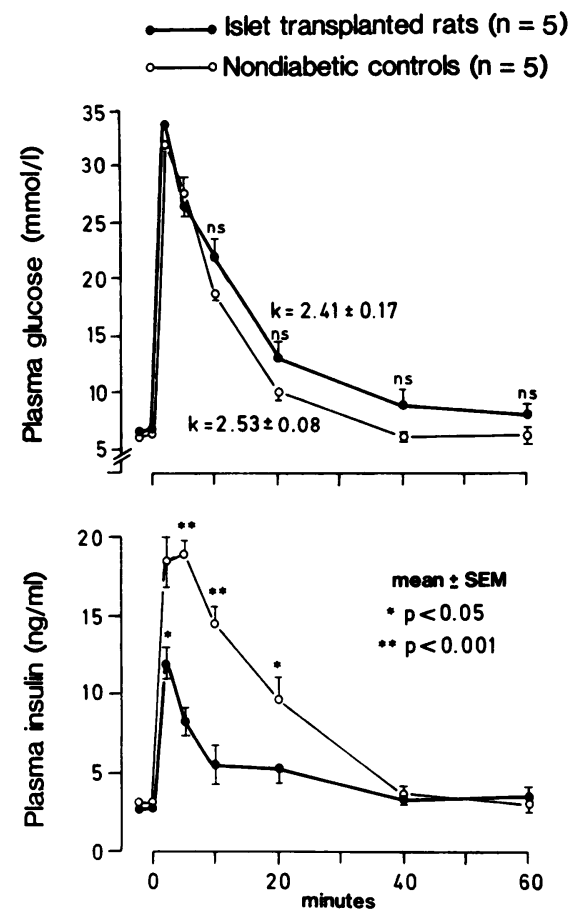

Fig. 2 Plasma glucose and insulin concentrations in conscious unstressed rats during intravenous GTT $(1 \mathrm{~g} / \mathrm{kg})$. The curves compare islet-transplanted rats to non-diabetic controls 14 to 16 weeks after transplantation. Glucose was administered at $0 \mathrm{~min}$, the early time points were two, five, and 10 minutes, $n s=\mathrm{P}>0.05$, lng insulin $=24 \mu U$.

Table Incremental insulin and glucose areas

\begin{tabular}{|c|c|c|c|}
\hline & Transplants & $\mathbf{P}$ & Controls \\
\hline \multicolumn{4}{|c|}{ Incremental areas during IVGTT $(60 \mathrm{~min})$} \\
\hline Glucose areas & $423 \pm 73$ & $>0 \cdot 10$ & $308 \pm 17$ \\
\hline Insulin areas & $121 \pm 19$ & $<0.005$ & $304 \pm 32$ \\
\hline \multicolumn{4}{|c|}{ Incremental glucose areas during oral GTT (60 $\mathrm{min})$} \\
\hline Without insulin injectio & $\begin{array}{c}307 \pm 63 \\
<0.005\end{array}$ & $<0.01$ & $\begin{array}{c}71 \pm 6 \\
>0.50\end{array}$ \\
\hline With insulin injection & $155 \pm 45$ & $>0 \cdot 10$ & $76 \pm 7$ \\
\hline \multicolumn{4}{|c|}{ Incremental insulin areas during oral GTT $(60 \mathrm{~min})$} \\
\hline Without insulin injectio & $\begin{array}{l}128 \pm 20 \\
>0.80\end{array}$ & $<0.005$ & $\begin{array}{c}260 \pm 27 \\
>0 \cdot 10\end{array}$ \\
\hline With insulin injection & $131 \pm 28$ & $>0 \cdot 30$ & $190 \pm 49$ \\
\hline \multicolumn{4}{|c|}{ Incremental insulin areas during first $5 \mathrm{~min}$ of oral GTT } \\
\hline Without insulin injectio & $\begin{array}{l}2.6 \pm 1.2 \\
<0.01\end{array}$ & $<0.05$ & $\begin{array}{l}11 \cdot 3 \pm 3 \cdot 0 \\
>0 \cdot 10\end{array}$ \\
\hline With insulin injection & $14 \cdot 2 \pm 1.9$ & $>0 \cdot 10$ & $20 \cdot 3 \pm 2 \cdot 8$ \\
\hline
\end{tabular}

The areas were calculated by integrating the insulin or glucose values above basal for each individual rat. Statistical comparison was by Student's unpaired $t$ test when transplanted rats were compared with controls and by the paired, when the rats with insulin injection were compared with themselves without insulin injection. Values are mean $\pm S E M, n=5$, for both transplanted rats and controls. $(\mathrm{n}=5)$ and was normalised by transplantation (see below). Non-diabetic controls had plasma glucose values of $6.9 \pm 0.6 \mathrm{mmol} / 1(\mathrm{n}=5)$ before sham operation. At death the insulin content of the pancreas in transplanted rats was $0.50 \pm 0.05 \%$ of non-diabetic controls and that of diabetic controls was $0.46 \pm$ $0 \cdot 22 \%$.

\section{GLUCOSE TOLERANCE TESTS}

Permanent cardiac catheters for use in glucose tolerance tests were implanted after the weight of the transplanted rats had caught up with that of the agematched controls (13th to 15th week, Fig. 1). Tests were started one week after this operation when the rats had regained their preoperative weight. The mean basal plasma glucose values for all the tests described below (calculated from the mean of six values for each animal) were $6 \cdot 8 \pm 0 \cdot 2$ for five non-diabetic controls, and $6 \cdot 8 \pm 0 \cdot 1 \mathrm{mmol} / 1$ for five transplanted rats. The mean basal plasma

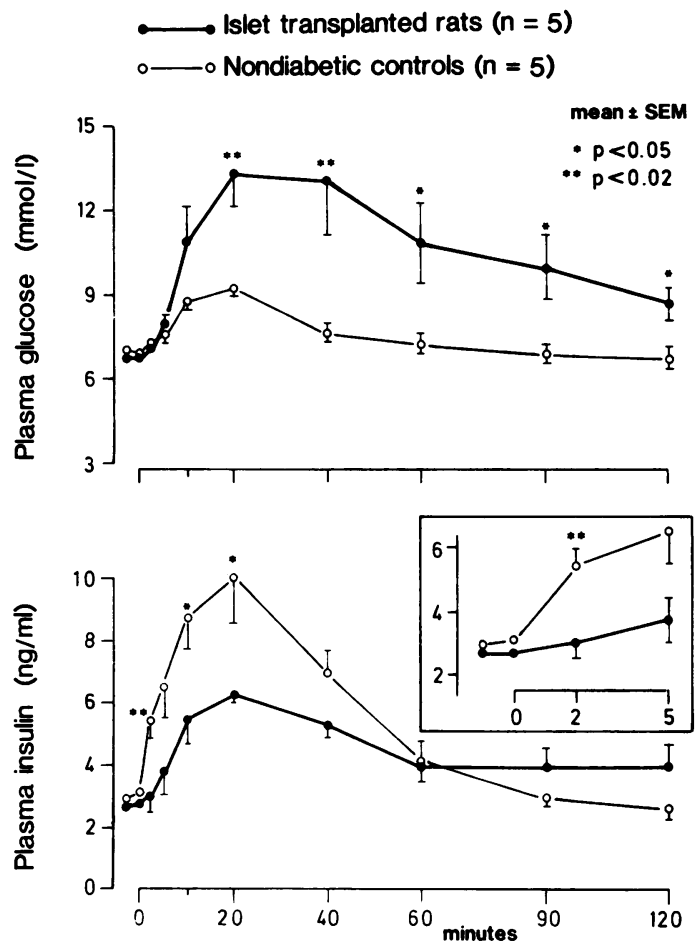

Fig 3 Plasma glucose and insulin concentrations in conscious unstressed rats during oral GTT $(1 \mathrm{~g} / \mathrm{kg})$. The curves compare the oral glucose tolerance of the same animals as Fig. 2. Tests were started (0 min) when the rat spontaneously began to take the glucose. Early blood sampling was at two, five and 10 minutes. The insert shows the first 5 min of the insulin curves on an expanded scale, $1 \mathrm{ng}$ insulin $=24 \mu U$. 

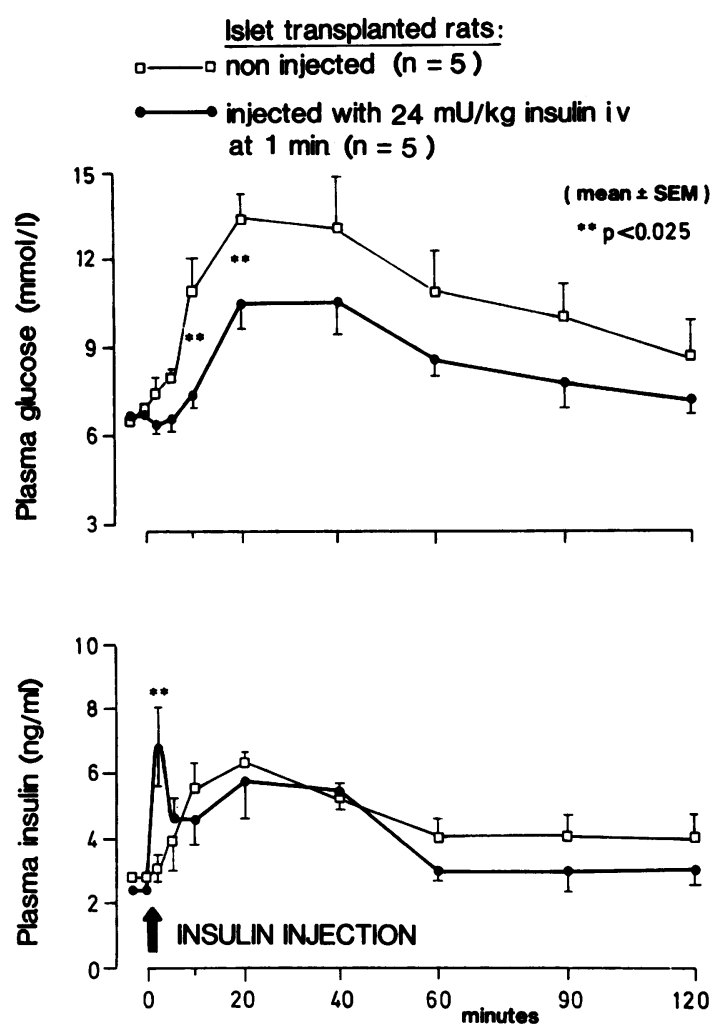

Fig. 4 Effect of insulin injection during the preabsorptive period on oral glucose tolerance in islettransplanted rats. The curves refer to the same transplanted rats as do Figs 2 and 3. Tests were started when the rat spontaneously began to take the glucose. Exogenous insulin was administered exactly one minute after this in a dose calculated to mimic at two minutes the insulin level found in controls without insulin injection (see Fig. 3, insert). Early blood samples were taken at two, five and 10 minutes. Statistical comparison was by Students two-tailed paired t test.

insulin values were $2.90 \pm 0.19 \mathrm{ng} / \mathrm{ml}$ for five nondiabetic controls, and $2 \cdot 70 \pm 0.34 \mathrm{ng} / \mathrm{ml}$ for five transplanted rats. Thus, transplantation had normalised both basal insulin and glucose concentrations. Moreover, in each individual test the basal plasma insulin or glucose levels were similar for transplanted rats and controls.

INTRAVENOUS GTT $(1 \mathrm{~g} / \mathrm{kg})$

During the intravenous glucose tolerance test the glucose values of transplanted rats were not significantly different from controls (Fig. 2), although they showed a tendency to have slightly higher values at some time points. The mean $\mathrm{K}$-value for transplanted rats $(2 \cdot 41 \pm 0 \cdot 17)$ was similar to that of non-diabetic controls $(2 \cdot 53 \pm 0.08, \mathrm{P}>0.40)$. Trans- planted and control rats both showed a rapid insulin response with maximal insulin concentrations achieved at two minutes. The insulin concentrations, however, were significantly lower in transplanted rats during the first 20 minutes, and the incremental insulin areas were smaller in transplanted rats than in controls (Table). No significant difference was seen in the incremental glucose areas.

ORAL GTT $(1 \mathrm{~g} / \mathrm{kg}, 2 \mathrm{~g} / \mathrm{kg})$

In contrast with the plasma glucose values reached after intravenous glucose, during oral GTT after 20 minutes consistently higher plasma glucose levels were observed in transplanted rats than in controls (Fig. 3). Mean values of plasma glucose above $11 \mathrm{mmol} / 1$ were found at 20 and 40 minutes. The integrated incremental glucose area was also significantly greater in transplanted rats than in controls (Table).

As early as two minutes after the start of the oral glucose ingestion, before a significant rise in plasma glucose could be lobserved, non-diabetic controls

Nondiabetic controls:
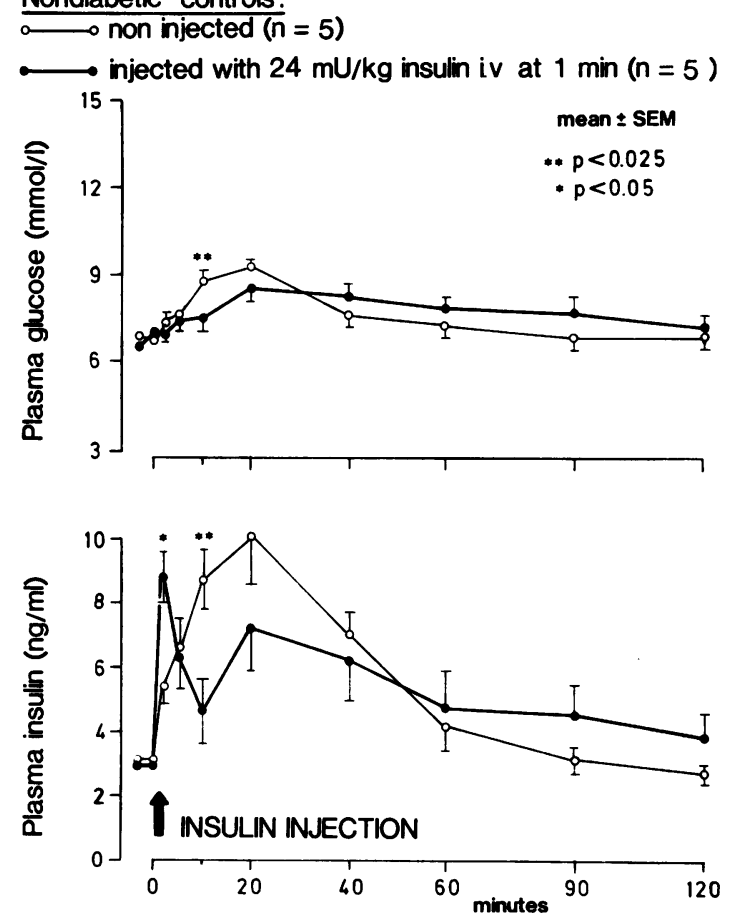

Fig. 5 Effect of an insulin injection during the preabsorptive period on oral glucose tolerance in non-diabetic control rats. The curves show the effects in control rats of the same insulin injection as was given to transplanted rats (compare with Fig. 4). These rats are the same as in Figs 2 and 3. 
exhibited a significant increase of plasma insulin above their own basal level (mean increase $2 \cdot 5 \pm 0 \cdot 6$ $\mathrm{mg} / \mathrm{ml}, \mathrm{P}<0.02$ ), whereas transplanted rats showed no such rise in plasma insulin at the same two minute time point (mean increase $0 \cdot 2 \pm 0 \cdot 3 \mathrm{ng} / \mathrm{ml}$ ). The incremental 60 minute insulin area for transplanted rats was about $50 \%$ that of controls (Table). An oral GTT using a larger dose $(2 \mathrm{~g} / \mathrm{kg})$ was performed only in three transplanted rats. The 60 minute incremental insulin area was $62 \%$ greater $(\mathrm{P}<0.05)$ than that during the test with $1 \mathrm{~g} / \mathrm{kg}$ in the same rats. Therefore, islet-transplanted rats had not reached the limit of their insulin secretory capacity during the $1 \mathrm{~g} / \mathrm{kg}$ oral GTT. While overall insulin release in transplanted rats was reduced during oral GTT compared with that of controls, there was a disproportionate decrease during the early part of the test (see Table), no rise in plasma insulin being observed during the preabsorptive period.

ORALGTT ( $1 \mathrm{~g} / \mathrm{kg})$ WITH INTRAVENOUS

INSULIN INJECTION

To investigate whether the absence of preabsorptive insulin response influenced subsequent glucose tolerance in transplanted rats, a small dose of insulin was given intravenously through the indwelling catheter. The dose injected was $24 \mathrm{mU} / \mathrm{kg}$ Actrapid, given exactly one minute after the rat had spontaneously started to drink the glucose solution. In transplanted rats this resulted in an increase of the plasma insulin concentration of $3.6 \pm 1.4 \mathrm{ng} / \mathrm{ml}$ at two minutes compared with the level measured in the test without insulin injection in the same rats (Fig. 4). No effect of the insulin injection on plasma insulin levels was detectable at five minutes nor at any later time point.

The small and transitory plasma insulin increase was associated with a striking overall amelioration of the oral glucose tolerance profile. The decrease of plasma glucose induced by the insulin injection was significant at 10 and 20 minutes. Furthermore, although every individual rat exhibited lower values also at 40, 60, and 90 minutes this did not reach statistical significance $(0.05<\mathrm{P}<0.10$ for all points) because the decrease achieved varied. The improvement in glucose tolerance was also evident from the highly significant decrease in the incremental glucose area induced by the insulin injection (Table).

Although non-diabetic controls have preabsorptive insulin release, intravenous insulin injections at one minute were also carried out in that group (Fig. 5). This resulted in an increase in plasma insulin of $3 \cdot 2 \pm 1 \cdot 3 \mathrm{ng} / \mathrm{ml}$ at two minutes above that found in the test without injection. Apart from this increase, the only detectable effect on plasma insulin levels was a decrease at 10 minutes compared with the tolerance test without insulin injection. This coincided with a small, but significant, decrease of plasma glucose at the same time (10 minutes).

Results can be summarised by describing the changes in incremental glucose and insulin areas (Table). In transplanted rats without insulin injection during the preabsorptive period the glucose areas were increased and insulin areas were decreased compared with controls. The insulin injection given in the preabsorptive period increased the five minute insulin area to a value comparable with that found in controls without insulin injection, whereas the 60 minute incremental insulin area was unchanged. By contrast, the insulin injection markedly reduced the incremental glucose area to a value which, although still retaining some tendency to be greater than, was not significantly different from that of controls.

\section{Discussion}

This study clearly demonstrates that, in transplanted rats, known to have absent cephalic phase insulin secretion, ${ }^{34}$ an intravenous injection of insulin which mimicked this early phase of insulin release, both with respect to its timing and to its magnitude, exerted a remarkable effect on oral glucose tolerance. It is striking that, in transplanted rats, although plasma insulin levels at five minutes and later were not affected by the small dose of exogenous insulin, a marked improvement in glucose levels was achieved over the whole observation period of the glucose tolerance test. When the effect of the intravenous insulin injection at one minute is described in terms of integrated insulin and glucose areas the effect of injection in enlarging the insulin area was limited to the first five minutes, whereas the incremental insulin area over 60 minutes in transplanted rats was not affected. The 60 minute glucose area in transplanted rats was, however, reduced by half, while the insulin injection had no effect on the glucose area in controls which have intact cephalic phase insulin release. Even in controls, the transient increase in plasma insulin levels at two minutes, superimposed on an intact cephalic phase, exerted a small but significant effect on plasma glucose and on plasma insulin levels seen only at 10 minutesthat is, after exogenous insulin had disappeared from the blood. Therefore, even normal rats wilh an intact cephalic phase appear to be sensitive to small alterations in plasma insulin in the preabsorptive period.

Overall insulin output, as measured as insulin levels in peripheral blood, was less in transplanted 
rats than in controls during both oral and intravenous glucose tolerance. Caution should, however, be taken in extrapolating from peripheral plasma insulin levels to the amount secreted. In normal rats, $50 \%$ of secreted insulin can be extracted during one passage through the liver, ${ }^{16}{ }^{17}$ whereas no such data exist for rats with islets transplanted to the liver where regions of low and high insulin concentrations are found within the organ. The insulin areas of controls during an oral GTT were comparable with those during an intravenous GTT (Table). The insulin areas of transplanted rats were reduced by a similar amount during both tests. For the intravenous GTT, the insulin output was sufficient to normalise the K-values, whereas the oral GTT remained clearly abnormal. While during the intravenous GTT the onset of insulin release occurred as early in transplanted rats as in controls, during the oral GTT transplanted rats showed a clear delay in their insulin response.

The lack of early insulin response during oral GTT can be attributed, at least in part, to a missing cephalic phase of insulin release. ${ }^{34}$ This phase of insulin release occurs before the absorption of nutrients, ${ }^{3418-22}$ is a reflex that can be triggered by food-related stimuli in the mouth, and results in stimulation of the $\beta$-cells probably via efferent fibres of the vagus nerve. ${ }^{422}{ }_{23}$ Physiological importance of cephalic phase insulin secretion in oral glucose tolerance has been shown in experiments where the reflex has been by-passed in otherwise intact rats with permanent gastric catheters. Fifteen and 20 minutes after intragastric administration of glucose, plasma glucose levels were higher and plasma insulin levels were lower than when the same load was given orally. ${ }^{4}$ Higher plasma glucose concentrations were also found after intragastric administration of a mixed meal. ${ }^{19}$ After abolition of the reflex by vagotomy ${ }^{21}$ otherwise intact rats showed much higher plasma glucose levels during an oral glucose tolerance test than did normal controls. ${ }^{4}$ Cephalic phase insulin release can be abolished in dogs by chemical vagotomy-that is, atropinisation. ${ }^{23}$ In man atropinisation has been shown to cause deterioration of oral glucose tolerance while intravenous glucose tolerance remained intact. ${ }^{24}$ It is not surprising, therefore, that islettransplanted rats, with presumably vagotomised $\beta$-cells and no cephalic phase insulin release, ${ }^{24}$ should exhibit abnormal oral glucose tolerance, even when intravenous glucose tolerance has been normalised. Whether, in addition, gastrointestinal hormones such as gastric inhibitory polypeptide hormones such as gastric inhibitory polypeptide ${ }^{1}$ and gastrin, ${ }^{25}$ which play a role in the insulin response to oral glucose, may have contributed to this phenomenon remains to be established. It seems unlikely, however, that their secretion would be abnormal in transplanted rats with intact innervation of the gastrointestinal tract and normalised body weight.

While decreased insulin secretory capacity not related to cephalic phase may have contributed to the pathological $1 \mathrm{~g} / \mathrm{kg}$ oral GTT in islet-transplanted rats, results from the $2 \mathrm{~g} / \mathrm{kg}$ test demonstrate that the transplanted rats had not reached the limit of their insulin secretory capacity during the $1 \mathrm{~g} / \mathrm{kg}$ test. The principal observation reported here is that an artificially reestablished 'cephalic phase insulin response' resulted in remarkably improved oral glucose tolerance most clearly seen some time after exogenous insulin has disappeared from the blood. A preabsorptive increase of $2.5 \mathrm{ng} / \mathrm{ml}$ in peripheral plasma insulin in controls two minutes after oral glucose may seem rather small. However, the increase in portal vein insulin concentrations at that time is almost certainly much greater, a finding that has been demonstrated in dogs during the first five minutes of an oral GTT. ${ }^{26}$ In man, portal insulin levels are twice as high as in the periphery in the basal state and may be as much as 10 times greater when insulin release is stimulated. ${ }^{27}$ In addition, it has been shown that the disappearance rate of intraportally injected insulin is greater than that of insulin injected into the periphery. ${ }^{28}$ Therefore, an insulin injection calculated to mimic peripheral insulin levels at two minutes probably does not overestimate the amount of insulin actually secreted from the pancreas during the preabsorptive phase. In addition, insulin secreted into the portal circulation is more effective in improving the metabolic state of pancreas-transplanted rats than is insulin secreted into the periphery. ${ }^{29}$ Nevertheless, the peripheral injection of a small amount of insulin caused striking changes in overall oral glucose tolerance of islet-transplanted rats. This result suggests an important physiological role for the neurally-mediated cephalic phase insulin response.

After intravenous glucose administration, the liver accounts for about $10 \%$ of the glucose metabolised $^{30}$ as opposed to $60 \%$ after oral administration of glucose..$^{30} 31$ In general, the function of cephalic phase responses is to prepare the gastrointestinal tract to digest and absorb food and to prepare the viscera to metabolise and store nutrients. ${ }^{22}$ The primary physiological role of cephalic phase insulin secretion may thus be to prime the liver for the uptake of glucose absorbed from the intestines. Pathological oral glucose tolerance may, therefore, occur when cephalic phase insulin secretion is absent and the liver is not prepared for this task. 
The authors are grateful to Mrs Liza Cavillier, Mrs Danielle Nappey, and Miss Dominique Rutschmann for their excellent technical help. This work was supported by grant nos. 3.774.0.76, 3.154.0.77, 3.487.0.79 of the Swiss National Science Foundation and NIH grant no. R01 AM 25220-01.

\section{References}

${ }^{1}$ Creutzfeldt W. The incretin concept today. Diabetologia 1979; 16: 75-85.

${ }^{2}$ Trimble ER, Siegel EG, Berthoud H-R, Renold AE. Intraportal islet transplantation: functional assessment in conscious unrestrained rats. Endocrinology 1980; 106: 791-7.

${ }^{3}$ Berthoud H-R, Trimble ER, Siegel EG, Bereiter DA, Jeanrenaud B. Cephalic phase insulin secretion in normal and pancreatic islet transplanted rats. Am J Physiol, 1980; E336-40.

${ }^{4}$ Louis-Sylvestre J. Relationship between two stages of prandial insulin release in rats. Am J Physiol 1978; 235: E103-11.

${ }^{5}$ Brunzell JD, Robertson RP, Lerner RL et al. Relationship between fasting plasma glucose levels and insulin secretion during intravenous glucose tolerance tests. J Clin Endocrinol Metab 1976; 42: 222-9.

${ }^{6}$ Cerasi E, Luft R, Efendic S. Decreased sensitivity of the pancreatic beta cells to glucose in prediabetic and diabetic subjects. A dose response study. Diabetes 1972; 21 : 224-34.

${ }^{2}$ Fischer U, Hommel H, Ziegler M, Jutzi E. The mechanism of insulin secretion after oral glucose administration. III. Investigations on the mechanism of a reflectoric insulin mobilization after oral stimulation. Diabetologia 1972; 8: 385-90.

${ }^{8}$ Albisser AM, Leibel BS, Ewart TG, Davidovac Z, Botz CK, Zingg W. An artificial endocrine pancreas. Diabetes 1974; 23: 389-96.

-Pipeleers DG, Pipeleers-Marichal MA, Karl IE, Kipnis DM. Secretory capability of islets transplanted intraportally in the diabetic rat. Diabetes 1978; 27: 817-24.

${ }^{10}$ Lacy, PE, Kostianovsky M. Method for the isolation of intact islets of Langerhans from the rat pancreas. Diabetes 1967; 16: 35-9.

${ }^{11}$ Steffens AB. A method for frequent sampling of blood and continuous infusion of fluids in the rat without disturbing the animal. Physiol Behav 1969; 4: 833-6.

${ }^{12}$ Halban PA, Berger M, Offord R. Distribution and metabolism of intravenously injected tritiated insulin in rats. Metabolism 1979; 28: 1097-104.

${ }^{13}$ Kenny J. Extractable glucagon of the human pancreas. $J$ Clin Endocrinol Metab 1955; 15: 865-71.

${ }^{14}$ Bergmeyer HU, Bernt E. Methods of enzymatic analysis. Bergmeyer HU, ed. New York: Academic Press 1963: $123,130$.

${ }^{15}$ Herbert V, Lau K-S, Gottlieb CW, Bleicher SJ. Coated charcoal immunoassay of insulin. $J$ Clin Endocrinol Metab 1965; 25: 1375-84.
${ }^{16}$ Karakash C, Assimacopoulos-Jeannet F., Jeanrenaud B. An anomaly of insulin removal in perfused livers of obese-hyperglycemic (ob/ob) mice. J Clin Invest 1976; 57: 1117-24.

${ }^{17}$ Mondon CE, Olefsky JM, Dolkas CB, Reaven GM. Removal of insulin by perfused rat liver: effect of concentration. Metabolism 1975; 24: 153-60.

${ }^{18}$ Hommel H, Fischer U, Retzlaff K, Knöfler H. The mechanism of insulin secretion after oral glucose administration. II. Reflex insulin secretion in conscious dogs bearing fistulas of the digestive tract by shamfeeding of glucose or tap water. Diabetologia 1972; 8: 111-6.

${ }^{19}$ Steffens AB. Influence of the oral cavity on insulin release in the rat. Am J Physiol 1976; 230: 1411-15.

${ }^{20}$ Strubbe JH, Steffens AB. Rapid insulin release after ingestion of a meal in the unanesthetized rat. $\mathrm{Am} \mathrm{J}$ Physiol 1975; 229: 1019-22.

${ }^{21}$ Louis-Sylvestre J. Preabsorptive insulin release and hypoglycemia in rats. Am J Physiol 1976; 230: 56-60.

${ }^{22}$ Powley TL. The ventromedial hypothalamic syndrome, satiety, and a cephalic phase hypothesis. Psychol Rev 1977; 84: 89-126.

${ }^{23}$ Fischer U, Hommel H, Freyse EJ, Fiedler H. Der Mechanismus der Insulinsekretion nach oraler Glukose verabreichung. IV. Verhinderung der reflektorischen Frühphase des Plasmainsulinanstiegs durch Atropin. Endokrinologie 1975; 65: 91-8.

${ }^{24}$ Henderson JR, Jeffrys DB, Jones RH, Stanley D. The effect of atropine on the insulin release caused by oral and intravenous glucose in human subjects. Acta Endocrinol 1976; 83: 772-80.

${ }^{25}$ Rehfeld JF, Stadil F. The effect of gastrin on basal and glucose-stimulated insulin secretion in man. $J$ Clin Invest 1973; 52: 1415-26.

${ }^{26}$ Hommel HH, Fischer U. The mechanism of insulin secretion after oral glucose administration. V. Portal venous IRI concentration in dogs after ingestion of glucose. Diabetologia 1977; 13: 269-72.

${ }^{27}$ Blackard WG, Nelson NC. Portal and peripheral vein immunoreactive insulin concentrations before and after glucose infusion. Diabetes 1970; 19: 302-6.

${ }^{28}$ Navelesi R, Pilo A, Ferrannini E. Insulin kinetics after portal and peripheral injection of $\left[{ }^{125} I\right]$ insulin. II. Experiments in the intact dog. Am J Physiol 1976; 230: 1630-6.

${ }^{29}$ Brown J Mullen Y, Clark WR, Molnar IG, Heininger D. Importance of hepatic portal circulation for insulin action in streptozotocin-diabetic rats transplanted with foetal pancreases. J Clin Invest 1979; 64: 1688-94.

${ }^{30}$ De Fronzo RA, Ferrannini E, Hendler R, Wahren J, Felig P. Influence of hyperinsulinemia, hyperglycemia and the route of glucose administration on splanchnic glucose exchange. Proc Natl Acad Sci USA, 1978; 75: 5173-7.

${ }^{31}$ Felig P, Wahren J, Hendler R. Influence of oral glucose injection on splanchnic glucose and gluconeogenic substrate metabolism in man. Diabetes 1975; 24: 468-75. 